(C) Dereito Vol.27, noEXT:63-96 (Xaneiro-Decembro, 2018) • ISSN 1132-9947

\title{
NEGOCIACIÓN LEGISLATIVA Y TÉCNICA NORMATIVA EN LA TRAMITACIÓN PARLAMENTARIA DE LA LEY DE TRANSPARENCIA Y BUEN GOBIERNO DE GALICIA
}

Legislative negotiation and normative technique in the parliamentary procedure of the Law of Transparency and Good Government of Galicia

DOI: http://dx.doi.org/10.15304/dereito.27.Ext.5786

\author{
Xosé Antón SARMiento MÉndez \\ Letrado Oficial Mayor \\ Parlamento de Galicia \\ xsarmiento@parlamentodegalicia.es
}

\section{Resumen}

Tras aludir a la situación de la transparencia en Galicia hasta 2016, se analizan los aspectos esenciales de la LGT que fueron objeto de negociación en el Parlamento de Galicia, de forma tal que se modificó el proyecto de ley enviado por el Gobierno. Es el caso de las obligaciones de publicidad activa, de los derechos de acceso o del control de dichas obligaciones. También hay ejemplos en la transición entre gobiernos o en las incompatibilidades y conflictos de intereses. Todo ello demuestra el relevante esfuerzo por llegar a ciertas transacciones y consensos en el tema de transparencia en la cámara gallega.

Palabras clave: Parlamento de Galicia, negociación, procedimiento legislativo.

\begin{abstract}
After referring to the situation of transparency in Galicia until 2016, the essential aspects of the LGT that were the object of negotiation in the Parliament of Galicia are analyzed, in such a way that the draft law sent by the Government was modified. This is the case of active advertising obligations, rights of access or control of those obligations. There are also examples in the transition between governments or in incompatibilities and conflicts of interest. All this demonstrates the relevant effort to reach certain transactions and consensus on the issue of transparency in the Galician chamber.
\end{abstract}

Keywords: Parliament of Galicia, negotiation, legislative procedure.

\section{SUMARIO}

1. LA TRANSPARENCIA EN GALICIA HASTA LA LGT.;- 2. PRINCIPALES CUESTIONES ABORDADAS POR LA LEY GALLEGA EN TRANSPARENCIA Y OBJETO DE NEGOCIACIÓN EN EL PROCEDIMIENTO LEGISLATIVO.;- 2.1. Obligaciones de publicidad activa.;- 2.2. Los derechos de los gallegos de acceso a la información.;- 2.3. Coordinación y control de las obligaciones de transparencia.;- 3. LOS MANDATOS REFERIDOS AL GOBIERNO Y

Recibido: 10/12/2017. Aceptado: 09/09/2018. 
ALTOS CARGOS.;- 3.1. Transición entre gobiernos y buen gobierno.;- 3.2. Incompatibilidades y conflictos de intereses.;- 4. BIBLIOGRAFÍA.

\section{LA TRANSPARENCIA EN GALICIA HASTA LA LEY DE 2016}

Donnarumma $^{1}$ ha destacado de forma clarificadora el papel del parlamento en la transparencia y control del gobierno con motivo de su estudio de la relación entre los poderes en la Francia actual y ello es interesante para valorar el contrapeso de poderes que se produce en Galicia por la aprobación de la nueva LGT. Lo es para también poder interpretar el alto grado de consenso y debate de la ley autonómica que como en su momento puso de manifiesto Santaolalla ${ }^{2}$ supone la superioridad del modelo basado en la dialéctica parlamentaria en cuanto obliga a ejercitar la mente y buscar argumentos y contraargumentos que resulten objetivamente creíbles. La presentación del proyecto de ley de transparencia en el parlamento en la sesión plenaria del 10 de noviembre de 2015 por parte del vicepresidente de la Xunta de Galicia remarcó la integración de la nueva norma dentro del denominado Programa de impulso democrático de la Xunta de Galicia. El gobierno gallego ${ }^{3}$, en su objetivo de promover la máxima transparencia de la gestión pública, puso en marcha este Programa de impulso democrático de la Xunta de Galicia 2015-2016 con un cuádruple alcance:

a. Incrementar y reforzar la transparencia en la actividad pública, a través de obligaciones de publicidad activa en la administración general y en las entidades instrumentales del sector público autonómico (es de destacar que la ley gallega no se preocupa de figuras conexas de gran importancia como los grupos de interés ${ }^{4}$ ).

b. Reconocer y garantir el acceso a la información, regulado como un derecho.

c. Establecer las obligaciones del buen gobierno que deben cumplir los responsables públicos, así como las consecuencias jurídicas derivadas de su incumplimiento.

d. La regeneración democrática en nuestra Comunidad Autónoma.

\footnotetext{
1 "Le régime semi-présidentiel. Une anomalie française". Revue française de droit constitutionnel, núm. 93, 2013, pp. 37 y ss.

2 "El debate parlamentario y el uso de la palabra", Revista de Derecho Político, UNED, núm. 86, enero-abril 2013, pp. 47 a 80.

3 http://cpapx.xunta.es/impulso-democratico. En todo caso como ha reseñado Manuel Villoria "la ciudadanía ha ido comprendiendo que la transparencia es un valor esencial en la vida democrática, un valor que no es finalista, sino instrumental, pero no por ello menos importante" (M. VILLORIA, "El largo camino hacia la transparencia en los ayuntamientos españoles", El consultor de los ayuntamientos, núm. 18, 30 de septiembre de 2015, p. 1983).

${ }^{4}$ Así lo hace de modo innovador la ley catalana como estudian Bartlett Castellá y Vèrnia Trillo en "La regulación del registro de grupos de interés en la ley 19/2014, del 29 de diciembre, de transparencia, acceso a la información pública y buen gobierno", Revista catalana de dret públic, núm. 51, 2015, pp. 191 y ss.
} 
Las instituciones públicas en general, y las regionales en particular, han asistido en los inicios del siglo $\mathrm{XXI}^{5}$ a una profunda transformación en materia de gestión y gobierno propiciada por la continua innovación en el ámbito de las tecnologías de la información y la comunicación y estas circunstancias están en la base de los cambios legales y administrativos que vivimos en nuestros días.

Sin embargo, de forma paralela al desarrollo de los medios que permiten una comunicación fluida y bidireccional entre representantes y representados, las administraciones públicas asisten actualmente al aumento de la desafección y desconfianza de la ciudadanía hacia las instituciones.

Así de un lado, la ciudadanía demanda una participación más activa en sus instituciones y en los procesos legislativos; mientras que por otro, critica la falta de respuesta y/o interés de las instituciones por atender sus demandas e involucrarles en los procesos de toma de decisión y precisamente como nos recuerdan las clásicas palabras de Kauffmann y Kraay la transparencia es "un flujo incremental de información oportuna y confiable de carácter económico, social y político, accesible a todos los actores afectados por una decisión pública".

En la misma línea, la implementación en las administraciones de los principios de transparencia pública, en la que están presentes los procesos de e-información y e-consulta, constituye en criterio de la mayor parte de nuestras instituciones la mejor respuesta a la desafección ciudadana y el primer paso para recuperar la confianza de los ciudadanos y ciudadanas en sus instituciones. De este modo, la e-democracia y la transparencia pública son hoy elementos inherentes a la democracia del siglo XXI y suponen un elemento angular en la actividad institucional que ponen de actualidad las ideas de Kant: "Todas las acciones relativas al derecho de los demás hombres, cuya máxima no sea susceptible de publicidad son injustas" ${ }^{\prime \prime}$.

En el ámbito español Victor Almonacid señala que sobre la materia concreta de transparencia, cabe reconocer el impacto y la influencia de la LETAI a la hora de despertar al legislador autonómico ${ }^{7}$, afirmación que

\footnotetext{
${ }^{5}$ El programa de actuaciones para el Buen Gobierno, aprobado en el Consejo de Ministros de 18 de febrero de 2005 afirmaba que "... supone la incorporación al Gobierno de España de las mejores prácticas del sector privado y la aplicación de las recomendaciones de las organizaciones internacionales. Con este programa se quiere garantizar que los altos cargos desarrollan su trabajo de acuerdo a lo que la sociedad espera de ellos, que los ciudadanos pueden depositar su confianza en los responsables de la Administración y que hay mecanismos adecuados para corregir los comportamientos que no estén a la altura de la democracia".

${ }^{6}$ I. KANT, Scritti politici e di filosofia della storia e del diritto, trad. It., Utet, Turín, 1956, p. 330.

7 Campos Acuña recuerda que "al margen de las posibles resistencias que pueden oponerse a la implantación de la administración electrónica, son otros aspectos, como el sistema de "voluntariedad" impuesto por la disposición final tercera de la LAE, la ausencia de medios y la falta de definición de una estrategia global involucrando a otras administraciones con competencias en la materia, los responsables de este escenario" (M. C. CAMPOS ACUÑA, "Entidades Locales y transparencia. Cinco riesgos a evitar en el
} 
avalan las hasta diez iniciativas legislativas autonómicas posteriores a la aprobación de la ley estatal, todo ello sin perjuicio de la aprobación de numerosas ordenanzas y reglamentos municipales, muchos de ellos inspirados en la Ordenanza tipo de la Federación Española de Municipios y Provincias (aprobada por su Junta de Gobierno el 27 de mayo de 2014) ${ }^{8}$.

El legislador gallego en la exposición de motivos de la ley autonómica de transparencia recuerda que la importancia del control ciudadano sobre la actividad gubernamental en una democracia queda acreditada desde los debates que precedieron a la promulgación de la primera Constitución democrática de la historia. En los llamados «papeles federalistas», pensadores como James Madison o Alexander Hamilton introducían los conceptos de «rendición de cuentas» o «controles y contrapesos» como elementos esenciales que se encuentran en la raíz de la democracia.

Una democracia que no puede ser entendida tan solo como mecanismo de elección de gobiernos mediante sufragio sino como un sistema de imperio de la ley, con las debidas garantías y tutelas de las libertades y de los derechos individuales de los ciudadanos y de las ciudadanas.

En ese sentido, los mecanismos de transparencia y de buen gobierno funcionan como contrapesos que garantizan la protección de la ciudadanía frente a hipotéticas arbitrariedades del poder público. Las incompatibilidades de las personas que ejerzan altos cargos, la publicidad de las actividades del gobierno ${ }^{9}$ y el examen ciudadano de toda esta información suponen mecanismos de control y de limitación del poder estatal ante las libertades civiles.

Jiménez Asensio ha clarificado afortunadamente que "la transparencia forma parte integrante de la noción de buena gobernanza. Ya el Libro Blanco de la Gobernanza de la Comisión Europea de 2001 incluía entre sus cinco apartados básicos el de transparencia, inmediatamente después de la participación ciudadana y antes de la rendición de cuentas. Efectivamente, en todos los esquemas conceptuales que se han desarrollado institucionalmente de la buena gobernanza se ha incluido

\footnotetext{
proceso de implantación", Revista Española de la Transparencia, núm. 1, 2015, p. 74). Por su parte Almonacid defiende terminantemente que "la administración electrónica es la premisa sine qua non de la transparencia" ("La administración electrónica que soporta la transparencia: una visión jurídico práctica", El consultor de los ayuntamientos, núm. 18,2015, p. 2002).

transparencia/

https://nosoloaytos.wordpress.com/2015/06/12/leyes-autonomicas-sobre-

9 Blanes Climent comentó el art. 6 del proyecto de reglamento de la ley de transparencia y muestra su decepción sobre la publicidad de las actividades normativas del gobierno: $\mathrm{El}$ art. 6.2 no permite la publicación de los proyectos de órdenes ministeriales de carácter normativo. El art. 7.c) de la LETAI contempla la obligación de publicar "Ios proyectos de reglamentos", todos, sin distinguir entre proyectos de reales decretos y órdenes ministeriales de carácter normativo, como indebidamente hace el art. 6 del Proyecto de Reglamento de la LETAI. http://miguelangelblanes.com/2015/06/11/eldecepcionante-proyecto-del-reglamento-de-la-ley-192013-de-transparencia/
} 
siempre la transparencia como uno de sus elementos nucleares de esa noción" 10 .

En el ordenamiento jurídico estatal, ya la propia Constitución prevé en su art. 105 como una obligación la regulación del acceso ciudadano a determinada información administrativa. Al mismo tiempo, el derecho fundamental a la participación en los asuntos públicos, enunciado en el art. 23, no se debe entender limitado, al derecho de sufragio sino a la capacidad de la ciudadanía de ser un actor fundamental en el seguimiento, en el control y en la vigilancia de la actividad de los poderes públicos $^{11}$ y así el Tribunal Europeo de Derechos Humanos le ha reconocido el carácter de derecho humano fundamental (Sentencia de 25 de junio de 2013. Caso Youth Initiative for Human rights contra Serbia).

Con esa vocación, las Cortes Generales aprobaron la LETAI. Una norma que es, en su mayor parte, de contenido básico y resulta aplicable a las instituciones autonómicas en el plazo de dos años desde su entrada en vigor, tal y como está indicado en la disposición última novena de dicha norma.

Por su parte la ley de Galicia trata de puntualizar los mandatos más genéricos de la norma estatal y:

a. establece las obligaciones de difusión de determinada información pública a través de internet, concretando un catálogo mínimo de datos que ofrecer.

b. regula el derecho de la ciudadanía a solicitar del gobierno cualquiera otra información pública que juzgue oportuna, concretando los límites de ese derecho y estableciendo la posibilidad, en todo caso, de recurso contra las resoluciones denegatorias emitidas por las administraciones.

Finalmente, dicha ley:

- establece unos principios básicos de buen gobierno para los altos cargos de las administraciones públicas estatales

- deja al cargo de cada una de ellas la legislación concreta sobre sus normas de conducta y control de las incompatibilidades.

En el entorno gallego, la rendición de cuentas había sido abordada por dos leyes específicas: por un lado, la Ley 9/1996, del 18 de octubre, de

10 Así lo hizo también el Consejo de Europa en el documento de 2007 sobre "Buena Gobernanza e Innovación" de los gobiernos locales y así lo están haciendo más recientemente diferentes niveles de gobierno en diferentes textos y proyectos normativos que se están impulsando en fechas recientes en España. http://rafaeljimenezasensio.com/documentos/. "Un ejemplo próximo en el tiempo es el Proyecto de Ley de Transparencia, Participación y Buen Gobierno del sector público vasco, donde aparecen en la exposición de motivos reiteradas invocaciones a la gobernanza" (http://www.irekia.euskadi.eus/es/debates/1049-proyecto-leytransparencia-participacion-ciudadana-buen-gobierno-del-sector-publicovasco?stage $=$ conclusions) . 
incompatibilidades de los miembros de la Xunta de Galicia ${ }^{12}$ y altos cargos de la Administración autonómica, y, por otro, la Ley 4/2006, del 30 de junio, de transparencia y buenas prácticas en la Administración pública gallega ${ }^{13}$.

Ambas normas tienen su eje en el deber fundamental, encomendado por el Estatuto de Autonomía a los poderes públicos gallegos, de facilitar la participación de todos los gallegos en la vida política, y tienen su sustento legal en el art. 28.1 del mismo estatuto, que reconoce la competencia de la Comunidad Autónoma gallega para regular el régimen jurídico de la Administración pública de Galicia.

Las dos leyes supusieron importantes avances en el control de la actividad pública en Galicia:

- La Ley 9/1996 fijó el primer régimen de incompatibilidades de los responsables públicos de Galicia, instaurando las precauciones necesarias para garantizar su objetividad e imparcialidad.

- La Ley 4/2006, por su lado, introdujo la transparencia como principio rector de la actividad de la Administración autonómica y supuso la concreción legal de prácticas hoy habituales como la publicación de la información sobre los convenios y contratos públicos ${ }^{14}$, las convocatorias de subvenciones y la resolución de estas o la información retributiva de los cargos públicos.

12 Sobre la cual puede consultarse X. A. SARMIENTO MÉNDEZ, "As incompatibilidades dos membros da Xunta de Galicia e demais altos cargos", Dereito. Revista xurídica da Universidade de Santiago de Compostela, vol. 5, núm. 1, 1996, pp. 331-353.

${ }^{13}$ Esther Arizmendi opina que: "Galicia no es la primera ley de transparencia que hace. Desde 2006 ya lleva hablando de transparencia. Es un tema que ahí preocupa y ocupa a los gobiernos que ha tenido en los últimos diez años. Ya ha recorrido mucho camino desde 2006 de forma voluntaria. Ese camino, ahora, ampliado y mejorado, es la Ley $12 / 2016$. Con lo cual, y al contrario de lo que ocurre en otros territorios, hay mucho tramo que la comunidad gallega ya tiene andado" (entrevista en el Faro de Vigo, de 3 de abril de 2016, que se puede ver en http://www.farodevigo.es/galicia/2016/04/03/esther-arizmendi-partidos-hablantransparencia/1434281.html).

14 Manuel Mesa Vila entiende que la documentación que forma parte de las ofertas presentadas por otros licitadores se considera información pública ya que obra en poder del órgano de contratación en el ejercicio de sus funciones, quedando, por lo tanto, sometida a derecho de acceso. "El único límite, es decir, la documentación que no es accesible sería aquella que el propio licitador justificadamente (por afectar a documentos secretos, a aspectos técnicos o comerciales, etc.) hubiese declarado confidencial. El órgano de contratación tendrá la potestad de determinar si tal calificación es correcta, reservándose la posibilidad de contravenir la calificación inicial dada por el licitador y permitir el acceso a los documentos" (M. MESA VILA, "Algunas cuestiones sobre el ejercicio del derecho de acceso a la información pública en materia de contratos del sector público" Contratación Administrativa Práctica, núm. 139, Sección Contratista versus Administración, septiembre 2015, editorial La ley). En una línea aperturista de la información en relación con los procedimientos contractuales puede reseñarse la Orden de 28 de enero de 2015 de la Junta de Andalucía, por la que se aprueba la retransmisión en directo a través de internet, en los procedimientos abiertos de contratación, de los actos de apertura pública de las ofertas de los licitadores. 
Las obligaciones de transparencia y ben gobierno exigidas por estas leyes fueron uniéndose, a lo largo de los años, otras obligaciones en leyes sectoriales reguladoras de materias como:

a. las subvenciones

b. la ordenación urbanística

c. las prestaciones sanitarias

d. el sistema de archivos

e. la calidad de los servicios públicos (Marcos Sagarzazu y Arranz Molinero señalan que en su día la adopción de los modelos de oficinas integrales de atención supuso ya un importante impulso a la transparencia de las instituciones con notable anticipación a las recientes normas sobre transparencia).

f. la Ley 16/2010, del 17 de diciembre, de organización y funcionamiento de la Administración general y del sector público autonómico de Galicia.

Esta evolución se plasma en la progresiva mejora de la evaluación que Transparencia Internacional lleva haciendo de la Xunta de Galicia en los últimos años. Así lo recordó el Vicepresidente de la Xunta en la presentación del proyecto de ley en el Parlamento de Galicia el 10 de noviembre de 2015, pues en palabras de Cacharro Gosende "el cumplimiento de la legislación de transparencia exige de nuestro sector público un comportamiento marcadamente proactivo con respecto a sus mandatos $^{\prime 15}$, algo que en el caso italiano se ha tratado de lograr con la creación, como recuerda Cifarelli, de la figura del responsable de la transparencia ${ }^{16}$.

Las siguientes páginas pretenden clarificar el iter legislativo de la norma poniendo de manifiesto las innovaciones en su contenido que provienen del ánimo de consenso existente entre las fuerzas políticas y que posibilitó acuerdos políticos importantes en el texto de la nueva ley si bien de modo mucho más intenso en lo referido a la regulación de la transparencia y el acceso a la información y mucho menos en lo tocante a la regulación del buen gobierno autonómico ${ }^{17}$.

${ }^{15}$ F. CACHARRO GOSENDE, "La asistencia provincial e insular a los municipios para la aplicación de la ley de transparencia", El consultor de los ayuntamientos, núm. 18, 2015, p. 2035.

16 R. CIFARELLI, "La trasparenza amministrativa dalla legge n. 241/1990 all accesso civico: spunti di riflessione". Studi parlamentari e di politica costituzionale, año 46, núm. 179-180, 2013, p. 43.

17 Para unas reflexiones acerca de la negociación legislativa en ámbitos presidencialistas puede consultarse Javier Aparicio, profesor del CIDE, que explicó que poner como moneda de cambio reforma político-electoral ante las otras grandes reformas puede incomodar a algunos "es parte natural de la negociación legislativa y de la negociación entre presidentes y legisladores en el mundo democrático". Entrevistado vía telefónica en el espacio de "A Fondo" que ese intercambio puede ser desafortunado, pero "pensemos en la alternativa de si no hubiera eso que hacemos discutimos tema por tema o que pasa". http://www.radioformula.com.mx 


\section{PRINCIPALES CUESTIONES ABORDADAS POR LA LEY GALLEGA Y OBJETO DE NEGOCIACIÓN EN EL PROCEDIMIENTO LEGISLATIVO}

Catalina Ruiz-Rico Ruiz ${ }^{18}$ señaló que la intensa proliferación de leyes autonómicas de transparencia precediendo a una normativa estatal sobre esta materia, genera susceptibilidades en torno a su constitucionalidad ante el riesgo de colisión con las previsiones del legislador básico.

Por esta razón la respuesta del legislador autonómico:

a. se ha retrasado en determinadas comunidades autónomas

b. en otras se ha optado por la remisión a la ley estatal en las disposiciones sobre transparencia actualmente aprobadas para eludir conflictos constitucionales.

La Xunta de Galicia expone en el Preámbulo de la ley que en cualquier caso, la creciente exigencia ciudadana de control público de la actividad de las instituciones, así como la necesidad de adaptar las leyes existentes en Galicia al nuevo marco legal derivado de la aprobación de nueva legislación básica, aconsejan la aprobación de un nuevo texto. Una nueva norma que, además de avanzar en los pasos dados por la legislación previa ${ }^{19}$ y superarlos, integre en un mismo texto toda la regulación referida a la rendición de cuentas de los poderes públicos gallegos:

a. en lo que respecta a los datos derivados de su actividad administrativa y gubernamental

b. en lo tocante a los mecanismos de control ${ }^{20}$ de las buenas prácticas por parte de las personas que tienen responsabilidades públicas.

Esta nueva norma, en los momentos previos a su remisión al Parlamento, estuvo sujeta a un proceso de participación ciudadana, que tendrá como resultado la incorporación de aportaciones ciudadanas a su redacción final. Por lo que respecta al fundamento competencial de esta norma, el título I se dicta en ejercicio de la competencia autonómica exclusiva en materia de organización de sus instituciones de autogobierno recogida en el art. 27.1 del Estatuto de Autonomía de Galicia, de la competencia de desenvolvimiento legislativo y ejecución de la legislación del Estado en materia de régimen jurídico de la Administración pública de Galicia recogida en los arts. 28.1 y 39 del mismo texto legal, en relación con el art. 148.1.1 de la Constitución, dentro del marco legislativo básico dictado por el Estado.

18 C. RUIZ-RICO RUIZ, "Transparencia y participación en el derecho autonómico: un análisis constitucional". Revista internacional de doctrina y jurisprudencia.

19 Manuel Sánchez de Diego Fernández de la Riva valoró negativamente la ley estatal: "Estamos desaprovechado una oportunidad para hacer algo realmente esencial para la democracia electrónica del siglo XXI, reconocer un derecho fundamental a acceder a la información pública. La Ley no se ajusta a los diez principios de la Coalición Pro Acceso y a las recomendaciones de la OSCE." http://sanchezdediego.blogspot.com.es/2014/04/elprincipio-de-transparencia-y-el.html

${ }^{20}$ El Consejo de Estado en su Dictamen de fecha 19 de julio de 2012 al Anteproyecto de Ley de Transparencia, Acceso a la Información Pública y Buen Gobierno, recordó que "para que un mandato sea auténticamente obligatorio es necesario prever las consecuencias que en cada caso hayan de derivarse de su incumplimiento". 
Por otro lado las materias del título II, bajo la rúbrica de "buen gobierno", tienen su fundamento:

a. en las competencias de la Comunidad Autónoma para regular por ley el alcance de la responsabilidad y el estatuto personal de miembros de la Xunta

b. en la competencia autonómica en materia de organización de sus instituciones de autogobierno, de conformidad con lo previsto en el art. 27.1 y 39 en relación con el art. 16 del Estatuto de Autonomía de Galicia 21 .

De este modo, la ley se estructura en un título preliminar y tres títulos, cada uno de ellos dedicado a la regulación de uno de los dos objetivos fundamentales mencionados en el propio nombre de la ley: la transparencia y el buen gobierno de las administraciones públicas autonómicas, además del régimen sancionador.

Así, en primer lugar, el título preliminar establece el objeto de la ley y marca aquellos principios por los cuales se deberá regir su aplicación. Los principios que enumera son:

a) Principio de transparencia de la actividad pública.

b) Principio de acceso libre y gratuito a la información pública.

c) Principio de accesibilidad universal de la información pública.

d) Principio de reutilización de la información (aspecto que según Márquez no debe utilizarse técnicamente como sinónimo de open data que se refiere al carácter gratuito de los datos)

e) Principios de honestidad, imparcialidad, objetividad y respeto al marco jurídico y a todas las personas en lo relativo a la actuación de los altos cargos.

La ley gallega define aquellos sujetos a los cuales serán aplicables las obligaciones de transparencia y regula, así mismo, la obligación de otros sujetos de colaborar con aquellos en la satisfacción de las solicitudes de información pública introduciendo, como novedad respecto del marco básico, la posibilidad de aplicar multas coercitivas en el caso de ausencia de esta necesaria colaboración ${ }^{22}$.

21 En su trabajo "Análisis en clave competencial del Proyecto de Ley estatal sobre Transparencia, Acceso a la Información Pública y Buen Gobierno", Clara Isabel Velasco Rico explica que los contenidos de la ley de transparencia estatal: "parece justificar la invocación de hasta tres títulos competenciales distintos por parte del Gobierno. De acuerdo con la disposición final octava, la futura ley de transparencia se dicta "al amparo de lo dispuesto en los arts. 149.1.1 a, 149.1.13a y 149.1.18 a de la Constitución", con la excepción de lo dispuesto en los dos primeros apartados del art. 8 y en el segundo epígrafe del art. 18" (C. I. VELASCO RICO, Revista d'Etudis Autonòmics i Federals, núm. 17, abril 2013, pp. 279-328.

${ }^{22}$ Martín Razquin aclara que Las comunidades autónomas y las entidades locales tienen nuevas obligaciones de transparencia tanto activa como pasiva. El régimen jurídico que instaura la LETAI es diferente de las obligaciones de transparencia específicas de la normativa contractual (Texto Refundido de la Ley de Contratos del Sector PúblicoTRLCSP-). Ahora ya no se trata de que los interesados (normalmente los licitadores admitidos a la licitación que participan en los procedimientos de adjudicación) tengan derecho a conocer las condiciones de ésta y sobre todo el acuerdo de adjudicación, tarea que ha sido bien delimitada por los acuerdos de los Tribunales Administrativos de Contratación Pública y los informes de las Juntas de Contratación Administrativa, en 
Debe destacarse que en el seno de la ponencia ${ }^{23}$ encargada de informar el proyecto de ley se acordó la incorporación en el art. 3 de un nuevo apartado de relevante alcance que dispuso:

"3. En lo concerniente a las obligaciones de suministro de información, la presente ley será de aplicación a cualquier entidad privada que reciba o gestione fondos públicos o cuya actividad tenga interés público o repercusión social en los términos previstos en el artículo siguiente."

No cabe duda de que nos encontramos ante un refuerzo cualitativo de los mandatos de la ley gallega que impone unos deberes de transparencia que van más allá de los operadores públicos ${ }^{24}$ y asumen el esquema anglosajón en materia de transparencia ("follow the money").

Por otro lado una manifestación muy evidente del alto grado de negociación legislativa a la que se llegó por los cinco ponentes que representaron a sus grupos parlamentarios en la tramitación de la ley es la incorporación en el informe de la ponencia de un artículo inexistente en el texto del proyecto de $\operatorname{ley}^{25}$ y que está llamado a efectivizar ciertos principios generales de aplicación de la ley cuando la norma sea aplicada por los intérpretes ya sea en el ámbito administrativo como en el judicial. Se trata del nuevo art. 5 que después del consenso de la ponencia dispone:

"Artículo 5. Fomento de la cultura de la transparencia

explicación de lo dispuesto en el art. 151.4 del TRLCSP. "Llega la transparencia Las Comunidades Autónomas y las entidades locales tienen nuevas obligaciones de transparencia tanto activa como pasiva."

http://www.obcp.es/index.php/mod.opiniones/mem.detalle/id.216/relmenu.3/chk.5c347f bbc2a398070d64d346c7eb895b

${ }_{23}$ Manejamos a estos efectos el texto oficial del Informe de la Ponencia publicado en el BOPG núm. 567, del 7.12.2015. un texto sumamente negociado y que en este sentido es un reflejo de mandatos como los contenidos en el capítulo IV "Instrumentos legislativos" del Acuerdo interinstitucional entre el Parlamento europeo, el Consejo de la Unión europea y la Comisión europea sobre la mejora de la legislación. Diario Oficial de la Unión Europea del 12 de mayo de 2016.

${ }^{24}$ La enmienda núm. 4 del Grupo Parlamentario de Alternativa Galega de Esquerda posibilitó que expresamente constase la aplicación de los deberes de información para: "Los partidos políticos, organizaciones sindicales, organizaciones empresariales y entidades privadas perceptoras de fondos públicos a que se refiere el art. 3 de la Ley 19/2013, de 9 de diciembre, de transparencia, acceso a la información pública y buen gobierno...". Recientemente, la presidenta del Consejo de Transparencia de España afirmaba: "Los partidos tienen todavía muchos deberes que hacer. Hablan mucho de transparencia y hacen de la transparencia su bandera pero ni funcionan siempre de manera democrática ni sus cuentas son claras. El ejemplo fundamental lo tienen que dar los partidos políticos, es ahí donde nace la regeneración democrática y donde hay que actuar de manera decidida. Los partidos no pueden solo hablar, tienen que dar ejemplo. Y el ejemplo aún no lo dan"(entrevista en el Faro de Vigo, de 3 de abril de 2016, que puede verse en http://www.farodevigo.es/galicia/2016/04/03/esther-arizmendi-partidoshablan-transparencia/1434281.html).

${ }^{25}$ Cuyo texto fehaciente puede consultarse en el BOPG núm. 531 fascículo 1, del 7.10.2015 
1. La Xunta de Galicia promoverá la cultura de la transparencia ${ }^{26}$ entre la ciudadanía con cursos, conferencias y cuantos otros medios estime oportunos para fomentar y divulgar los medios disponibles y animar al ejercicio del derecho de acceso a la información por parte de los ciudadanos.

2. Con ese mismo fin, la Xunta de Galicia hará público anualmente en el Portal de transparencia y Gobierno abierto un informe aprobado por la Comisión Interdepartamental de Información y Evaluación, en el cual se analizarán y expondrán, como mínimo, los aspectos siguientes:

a) Las estadísticas relativas al derecho de acceso ${ }^{27}$ a la información pública, con la inclusión del número de solicitudes presentadas y de los porcentajes de los distintos tipos de resolución a que dieron lugar.

b) Los datos sobre la información más consultada en el Portal de transparencia y Gobierno abierto, y sobre la más solicitada a través del ejercicio del derecho de acceso."

La enmiendas 63 y 64 del Grupo Parlamentario Mixto y la número 16 del Bloque Nacionalista Galego parecen estar en el origen de esta disposición como puede deducirse de su lectura en el Boletín Oficial de la Cámara ${ }^{28}$.

\subsection{Obligaciones de publicidad activa ${ }^{29}$}

En esta materia el trámite parlamentario de la ley gallega denota también importantes dosis de compromiso pues la redacción final del art. 6 . "Principios generales" es deudora de la transacción de una enmienda núm.

26 La Disposición adicional primera de la ley dispone respecto de la Formación del personal público que la Escuela Gallega de Administración Pública incorporará, dentro de su plan de formación, instrumentos específicos para formar al personal empleado público en los derechos y obligaciones regulados por esta ley. No fue aceptada la enmienda del Grupo Parlamentario Mixto que pretendía obligar por ley a la impartición de la formación con anterioridad a la entrada en vigor de la ley.

27 Piñar Mañas se ha declarado defensor de la fijación legal de un régimen sancionador que permita hacer realmente efectivo el derecho de acceso y tal vez sería interesante la publicación de las sanciones que a tal efecto puedan llegar a imponerse (J. L. PIÑAR MAÑAS, "Seguridad, transparencia y protección de datos: el futuro de un necesario e incierto equilibrio", Laboratorio de Alternativas, núm. 147, 2009).

${ }^{28}$ Puede consultarse el texto completo de las enmiendas de los grupos parlamentarios en el BOPG núm. 554, del 17.11.2015. 2. También puede comprobarse que la previsión del artículo de extensión de la obligación de suministrar información a: a) todas las personas físicas o jurídicas adjudicatarias de contratos; y b) todas las personas físicas o jurídicas beneficiarias de subvenciones, proviene de sendas enmiendas del BNG y del Grupo Mixto, pues no constaba expresamente en el proyecto de ley del Gobierno.

${ }^{29}$ Según las noticias del Consejo de Transparencia del Estado el sector público estatal contesta las solicitudes de información de los ciudadanos con calidad y puntualidad, pero debe mejorar en los instrumentos de publicidad activa. Primer informe de evaluación del cumplimiento de la Ley de transparencia en el sector público estatal. El análisis global a 41 fundaciones, 18 consorcios, 30 consejos generales de colegios profesionales y 150 sociedades mercantiles concluye que las entidades asumen la transparencia y consideran positiva su implantación. Así se recoje detalladamente y para un estudio más pormenorizado de estas cuestiones en http://www.consejodetransparencia.es/ct_Home/actualidad/noticias/hemeroteca/2016/0 4/20160426.htmI\#.VyM-MDFvHcc 
67 del Grupo Parlamentario Mixto que incorporó la actual previsión de los dos primeros apartados:

"1. Se entiende por publicidad activa el compromiso de los sujetos comprendidos en los apartados 1 y 2 del artículo 3 de publicar a iniciativa propia y de forma periódica, actualizada, clara, veraz, objetiva y fácilmente accesible toda aquella información relevante relativa a su funcionamiento, como medio para fomentar el ejercicio por parte de la ciudadanía de su derecho fundamental a la participación y al control sobre los asuntos públicos.

2. Las obligaciones de publicidad activa contenidas en este capítulo se entienden complementarias de las contempladas en la normativa básica y sin perjuicio de la aplicación de otras disposiciones específicas que prevean un régimen más amplio en materia de publicidad."

No cabe duda que la definición del numeral 1 del artículo resulta de gran interés pues su inexistencia en el proyecto no delimitaba con tanta precisión el alcance normativo.

Obligaciones de publicidad activa, adicionales a las fijadas por la normativa básica se contemplan en la nueva ley que, a su vez, amplía las establecidas por la Ley 4/2006, del 30 de junio, de transparencia y buenas prácticas en la Administración pública gallega. Así, se marcan nuevas obligaciones de publicidad sobre información institucional, de relevancia jurídica o en materias como relaciones con la ciudadanía ${ }^{30}$, contratación pública ${ }^{31}$, convenios, personal, patrimonio o información económica y presupuestaria $^{32}$.

La modificación del texto del proyecto de ley más destacable en la regulación del actual art. 7 vino causada por la aceptación de la enmienda del Grupo Popular sobre la inclusión del plan estratégico o de gobierno y la transacción de sendas enmiendas socialistas y una del Bloque Nacionalista Galego que se incorporan en lo referido a la publicación de las agendas de la actividad institucional pública de los miembros de la Xunta de Galicia y

\footnotetext{
${ }^{30}$ En el caso de la Iniciativa Legislativa Popular (ILP), el 80 por ciento de los parlamentos contempla esta figura en su reglamento, con requisitos que van de la recogida de 1 a 150.000 firmas para que la Iniciativa prospere y sea llevada a Pleno. Puede afirmarse que las asambleas encuestadas no facilitan la propuesta y desarrollo de la ILP a través de sus páginas web. Sólo el 16 por ciento dispone de un espacio web específico para presentar ILP y apenas un 8 por ciento cuenta con recogida de firmas online. Lo mismo ocurre con el fomento de la participación de la ciudadanía en las instituciones a través de los modelos de encuestas de opinión, presentes en el 12 por ciento de los casos, y de foros online, con un 20 por ciento.

${ }^{31}$ EI CTB consideró que no existía un perjuicio a sus intereses económicos el conocer las empresas cuyas deudas habían sido saldadas por aplicación del mecanismo de pago a proveedores, por lo que resolvió que debía concederse dicha información. Sin embargo denegó el acceso en casos de necesidad de elaboración de la información en la resolución 0318/2015- Acceso a información sobre Licitadores y Empresas clasificadas del Estado.

32 Resulta de particular interés comprobar la amplitud que se ha dado al acceso en cuestiones tradicionalmente opacas en el sistema español. Así el CTB, en respuesta a una reclamación, resolvió que la Memoria Técnica Justificativa que debe presentar anualmente la Iglesia Católica y relativa a los fondos percibidos a través de la asignación tributaria del IRPF es información pública no afectada por ninguno de los límites al derecho amparado por la LETAI.
} 
de las personas que ocupen altos cargos, que se mantendrán públicas, como mínimo, durante un año. El Consejo de Transparencia estatal considera muy importante la publicación de las agendas aunque no están afectadas por el principio de publicidad activa de la Ley de Transparencia. Sin embargo, las agendas contribuyen a formar en la ciudadanía un mejor conocimiento de la actividad pública y con ello facilitan el escrutinio de quien la dirige, constituyendo además una buena práctica que cada vez aparece con más frecuencia entre los responsables de la actividad pública. Respecto de los mandatos de publicación de información de relevancia jurídica la norma gallega después de la transacción de las enmiendas núm. 7 del Grupo Socialista y la 24 del Bloque Nacionalista Galego contiene un apartado c) que detalla: "La relación circunstanciada y motivada de los procedimientos de elaboración de anteproyectos de ley y de disposiciones administrativas de carácter general que estén en tramitación, a partir del momento en el que se produzca la aprobación del anteproyecto, indicando su objeto y estado de tramitación, así como la posibilidad que tienen las personas de remitir sugerencias y la forma de hacerlo". A mi juicio se trata de un aspecto de la transparencia muy útil que facilitará la participación política de los ciudadanos de Galicia y el control por parte de la ciudadanía de las potestades normativas de los poderes públicos y que se ve complementada con un mandato innovador desde la perspectiva de la técnica legislativa que ha sido introducido en el informe de la ponencia de la ley y sin enmienda previa alguna de los grupos constituyendo la categoría del derecho parlamentario español de las "enmiendas de consenso". Se trata de la nueva Disposición adicional séptima. Normativa comunitaria:

"En un plazo de ocho meses desde la entrada en vigor de la presente ley, la Xunta de Galicia regulará los mecanismos de planificación y evaluación normativa derivados del contenido de las recomendaciones europeas sobre better regulation.

Se regulará además la existencia de una memoria de análisis de impacto normativo ${ }^{33}$, como documento que integre todas las aportaciones recibidas por el órgano directivo impulsor de la norma, cualquiera que fuese su procedencia, y la respuesta motivada a las mismas. En el caso de las iniciativas legislativas, este documento será remitido al Parlamento junto con cada una de ellas".

El texto gallego contiene en su artigo 10 obligaciones específicas de información en materia de personal. Además de la información que se debe hacer pública según la normativa básica en materia de transparencia, los sujetos citados en el artigo 3.1, en el ámbito de sus competencias, también publicarán:

a) documentación jurídica:

- Las relaciones de puestos de trabajo, los cuadros de personal y los demás instrumentos de ordenación de personal de los

33 En una línea generalmente admitida en el Derecho comparado. Por todos puede consultarse Garrido Iglesias: "Tecnología para la transparencia legislativa" Departamento de Gestión de Información. Serie Bibliotecnología y Gestión de Información. Chile. 
ámbitos de función pública, sanitario y docente. El Consejo de Transparencia del Estado ha sido muy generoso en la admisión de reclamaciones sobre el acceso a información en este ámbito ${ }^{34}$.

- Las ofertas públicas de empleo o instrumento similar de gestión de la provisión de las necesidades de personal.

- Las convocatorias de procesos selectivos para el ingreso en cuerpos, escalas o categorías de personal empleado público y los miembros de los órganos designados para cualificarlos.

- Las convocatorias de procesos de provisión definitiva de puestos de trabajo.

b) documentación estadística ${ }^{35}$ :

- Efectivos de personal funcionario, laboral, sanitario e docente, así como a información sobre os efectivos de personal eventual en los términos previstos en el art. 32 da Ley 2/2015, del 29 de abril, de empleo público de Galicia. En este sentido es de recordar que el Consejo de Transparencia y Buen Gobierno ${ }^{36}$ ha estimado tres resoluciones en materia de Sanidad, concretamente: acceso a base de datos con información sobre reacciones adversas de medicamentos, declaraciones de intereses presentadas por los miembros del Plan Estratégico para el abordaje de la Hepatitis C en el Sistema Nacional de Salud y acceso al informe elaborado por la Agencia Española del Medicamento relativo a la restricción de la vacuna de la varicela a uso hospitalario. Este criterio pone de manifiesto el amplio margen de transparencia que le queda abierto a la Xunta en lo referido a los datos estadísticos que obren en su poder.

- Permisos para la realización de funciones sindicales, liberados e liberadas sindicales tanto de carácter institucional coma las dispensas sindicales, distribuidos según relación nominal de personas y organizaciones sindicales a las cuales están vinculados, así como todos los costes que estas originan.

- Crédito horario total que tiene cada organización sindical y su distribución según relación nominal de personas, así como todos los costes que estas originan.

\footnotetext{
34 Resolución 0307/2015- Contrato para la formación en materia de ofimática en el Ministerio de Fomento.

${ }^{35}$ Hay que recordar que en el caso de la ley estatal el CTB velará por el cumplimiento de las disposiciones de la Ley y el incumplimiento podrá dar lugar a procedimientos disciplinarios. Su regulación es objeto de críticas por parte de Hernández Jiménez en "El Consejo de Transparencia y Buen Gobierno", Actualidad Administrativa, núm. 3, Sección actualidad, marzo 2016, La Ley, p. 5.

${ }^{36} \mathrm{http}: / /$ www.consejodetransparencia.es/ct_Home/consejo/reclamaciones/novedades/20 15/12/2015-12-10-1.html\#.Vqi3Hm5zKe4
} 
- El perfil biográfico y la trayectoria profesional de los altos cargos. El $\mathrm{CTB}^{37}$ consideró que el nombre de las compañías que habían mantenido reuniones con el Ministerio de Economía y Competitividad en el marco de la transposición de la Directiva europea del Tabaco no era información auxiliar o de apoyo ni era necesaria una actividad previa de reelaboración para proporcionar su acceso. Esta resolución es un buen ejemplo de la concepción amplia de la obligación de información activa en los referido a la agenda de los responsables públicos en la línea de lo demandado por organizaciones como Transparencia Internacional.

- La relación de contratos ${ }^{38}$ de alta dirección, con indicación de las retribuciones anuales y de las indemnizaciones previstas al final del contrato.

- Las declaraciones de actividades y de bienes patrimoniales de los altos cargos en los términos previstos en el título II de la ley.

- Las convocatorias de procesos de provisión transitoria de puestos de trabajo y, de ser el caso, la relación actualizada de personas que integran las listas de selección de personal interino o temporal, por orden de prelación. En este sentido la actividad rogatoria de los parlamentarios gallegos después de la aprobación de la ley ha permitido el control de su cumplimiento ${ }^{39}$.

c) Documentación económica ${ }^{40}$ :

37

http://www.consejodetransparencia.es/ct_Home/consejo/reclamaciones/novedades/2015 /12/2015-12-10-2.html\#.Vqi3iW5zKe4

38 Debe dejarse constancia de la transacción de la enmiendas 59 y 60 del Bloque Nacionalista Galego, 32, 143 y 144 del Grupo Parlamentario Mixto y 38 y 39 del Grupo Parlamentario de Alternativa Galega de Esquerda por la que se logró un nuevo texto que integra la Disposición transitoria primera. Obligaciones de transparencia:"1. Las obligaciones en materia de publicidad activa no serán de aplicación a aquellos contratos formalizados, convenios firmados o subvenciones concedidas antes de la entrada en vigor de esta ley. 2 . Las obligaciones en materia de publicidad activa no serán de aplicación a aquellos proyectos de disposiciones de carácter general o de planes o programas plurianuales cuya tramitación se haya iniciado antes de la entrada en vigor de esta ley". La reforma de la ley navarra de 2016 dispone respecto de las indemnizaciones por cese en su art. 64. Publicidad de las cesantías: "1. Se harán públicas las prestaciones económicas que se abonen a ex miembros del Gobierno de Navarra o ex altos cargos de la Administración Pública contempladas en la citada Ley Foral 19/1996, de 4 de noviembre, cuya publicidad se articulará en la forma que se determine en la misma. 2. La publicidad de las prestaciones económicas a que se refiere este artículo se mantendrá hasta transcurridos dos años del final del mandato o cese del cargo público."

39 Sirva de ejemplo la pregunta oral en pleno de los diputados del Grupo Parlamentario del BNG núm. 49317. BOPG 631 del 19 de abril de 2016.

${ }^{40}$ La transacción de enmiendas del BNG y socialistas posibilitaron la incorporación en el segundo apartado del art. 11 del siguiente mandato innovador en el ordenamiento 
- Los importes de las retribuciones máximas autorizadas al personal regulado en la Ley 16/2010, del 17 de diciembre, de organización y funcionamiento de la Administración general y del sector público autonómico de Galicia. Este tipo de información se valora por Augusto Barbera ${ }^{41}$ como útil para valorar el funcionamiento del estado descentralizado en el cumplimiento del pacto de estabilidad en el caso italiano.

- Las cuantías de las retribuciones que resulten aplicables al personal funcionario, estatutario y laboral, y las condiciones para su devengo. En esta línea se encuentra la resolución del CTB que ha considerado que el acceso a información sobre el presupuesto de las delegaciones diplomáticas de España en el exterior no supone un perjuicio a las relaciones exteriores sino que es información de interés público.

- Las cuantías globales de las indemnizaciones por razón del servicio que resulten aplicables al personal empleado público.

- Los acuerdos o pactos reguladores de las condiciones de trabajo o de las retribuciones e incentivos, así como los convenios colectivos vigentes.

- Las retribuciones de los altos cargos previstos en el art. 34 de esta misma ley ${ }^{42}$.

- La información sobre los viajes de los altos cargos, indicando los objetivos, suministrada periódicamente al Parlamento de Galicia y las resoluciones de autorización del ejercicio de actividad privada previo cese de los altos cargos. Estas previsiones provienen de la negociación de sendas transacciones en el seno de la ponencia con enmiendas del Grupo Parlamentario Socialista y suponen un control añadido a las actividades durante y después del mandato del alto cargo.

\footnotetext{
jurídico gallego: "En particular, la Xunta de Galicia hará pública toda la información complementaria sobre sus presupuestos que sea remitida al Parlamento a lo largo del ejercicio, incluyendo una actualización trimestral en función de la ejecución presupuestaria, así como la liquidación anual".

${ }^{41}$ A. BARBERA, "Da un federalismo insincero ad un regionalismo "preso sul serio"? Una riflessione sull 'esperienza regionale", Studi parlamentari e di politica costituzionale, año 44, núm. 171-172, 1-2 trimestre 2011, pp. 19 y ss.

${ }^{42}$ El CTB dictó en el mes de mayo de 2015 una resolución por la que estimaba que se debía conceder el acceso al Plan de medios del Instituto de Crédito Oficial (ICO). En la resolución, el CTB consideraba que, si bien existe un previsible perjuicio económico derivado del acceso a dicha información debido a que quedaba limitada la capacidad de negociación de la central de medios con los medios de comunicación, el interés público en conocer el destino final de los fondos públicos destinados a la publicidad institucional era superior en este caso $y$, por lo tanto, prevalecía frente al perjuicio que pudiera ocasionarse.
} 
Pero no solo es importante la cantidad de los contenidos ofertados sino la calidad de estos, e incluso su formato. Por esto, el legislador autonómico recoge como modalidad preferente de difusión de la información pública los formatos abiertos, que permitan a la ciudadanía la reutilización ${ }^{43}$ de los datos públicos.

\subsection{Los derechos de los gallegos de acceso a la información}

Opina Joan Ridao que la Ley del Parlamento gallego 4/2006 al no mencionar los límites o restricciones en el acceso a la información, obliga a aunar su aplicación con la ley básica estatal o sería necesario que el legislador autonómico la adaptase a las nuevas previsiones normativas ${ }^{44}$.

La ley gallega de transparencia de 2016 aborda la regulación del derecho ciudadano al acceso a la información pública ${ }^{45}$, más allá de aquella que sea ofertada en virtud de lo dispuesto en materia de publicidad activa. De esta manera, se determinan el procedimiento pertinente, estableciendo la necesaria obligación de las administraciones públicas de facilitar a la ciudadanía aquella orientación y asesoramiento que precise, así como de proporcionarle modelos normalizados de solicitudes y canales electrónicos para tramitarlos. En coherencia con estos principios ya consagrados por la ley estatal el CTB ha entendido que los datos de los empleados públicos asistentes a reuniones oficiales son datos meramente identificativos relacionados con la actividad pública del órgano y que, como tales y como regla general, deben proporcionarse. En cuanto a los datos de representantes de asociaciones o entidades privadas representativas de organizaciones civiles relevantes en materia de transparencia y acceso a la información, el CTB consideró que, al asistir a las mencionadas reuniones no en el ámbito de su esfera privada o individual, la

\footnotetext{
${ }^{43}$ Así, Miguel Ángel Davara Rodríguez dice que "si el ciudadano tiene ese derecho, nace consecuentemente la correlativa obligación de todas las Administraciones Públicas a hacer interoperables los documentos electrónicos de cualquier índole que tengan para poder hacer efectivo el derecho del ciudadano" (M. A. DAVARA RODRÍGUEZ, "Cuestiones sobre interoperabilidad en las Administraciones Públicas", Actualidad Administrativa, núm. 9, Sección Administración del siglo XXI, septiembre 2015, Editorial La Ley).

${ }^{44}$ J. RIDAO, "La regulación de la transparencia y del acceso a la información pública en la esfera autonómica. Un estudio comparado", Revista General de Derecho Constitucional, núm. 19, 2014, pp. 1 y ss.

${ }^{45}$ Las previsiones del art. 24: "2. En el ejercicio de su derecho al acceso a la información pública se garantizará a la ciudadanía: a) La posibilidad de utilización de la información obtenida sin necesidad de autorización previa y sin más limitaciones que las derivadas de esta u otras leyes. b) La recepción de la información pública en formato electrónico o en papel, según haya indicado la persona solicitante. c) La recepción de la información pública en la lengua oficial de Galicia en la que la solicite. d) El conocimiento de las tasas y precios que, en su caso, sean exigibles para la obtención de copias o para la transposición de la información a formatos diferentes del original. e) La realización de propuestas y sugerencias tanto sobre la información demandada como sobre los formatos, programas o lenguajes informáticos empleados" son consecuencia también de la negociación legislativa en la ponencia de la ley al lograr transaccionar varias enmiendas del Grupo Parlamentario Mixto pues no existían expresamente en el proyecto de ley aprobado por el Consello de la Xunta.
} 
ponderación entre su derecho a la protección de datos y la necesaria transparencia de las reuniones con representantes públicos tenía como resultado la preeminencia de esta última.

El Vicepresidente de la Xunta en la presentación del proyecto de ley en sede parlamentaria ${ }^{46}$ señaló el paso adelante del contenido de la ley respecto de la normativa básica y su carácter avanzado incluso respecto a lo dispuesto "en países punteros en transparencia democrática como los Estados Unidos de América".

La transparencia según Lizcano ${ }^{47}$ está inherentemente unida al derecho a saber de los ciudadanos, que exigen de forma creciente estar suficientemente informados y tener un mayor grado de participación en las decisiones que les afectan. En este sentido la suscripción a los contenidos web mediante RSS supone un avance en las vías directas de información.

Resulta reseñable como la aceptación de una enmienda del mayoritario Grupo Parlamentario Popular supuso la incorporación en el art. 27 de un apartado 3 que establece: "En el ámbito del sector público autonómico, la competencia para la resolución de las solicitudes de acceso corresponderá a la persona titular de la secretaría general, la secretaría general técnica, la dirección general o la delegación territorial en el caso de la Administración general de la Comunidad Autónoma, y a la persona titular de los órganos de gobierno o ejecutivos de las entidades instrumentales del sector público que posean la información". Esta previsión resulta de todo punto necesaria y no constaba en el proyecto siendo un logro más a valorar del texto final del informe de la ponencia.

Recuerda Blanes Climent que la nueva LETAI $^{48}$ no contempla ningún refuerzo de los mecanismos que tiene el ciudadano para responder en los casos en que se incumpla la ley porque no se conteste a las solicitudes, no se facilite la información o se haga de forma incompleta. Se sustituyen los clásicos recursos de reposición y de alzada por una reclamación administrativa a presentar ante el Consejo de Trasparencia y Buen Gobierno -cuando se trate de la Administración General del Estado y entidades dependientes- 0 ante el organismo autonómico correspondiente -Administración Autonómica y Local-.

46 Una gran novedad del texto definitivo de la ley contenida en el art. 19 es la Información específica sobre las relaciones de la Xunta con el Parlamento de Galicia: "1. La Xunta de Galicia publicará en el Portal de transparencia y Gobierno abierto la relación de los acuerdos aprobados en el Parlamento de Galicia que afecten a sus competencias, detallando la fecha de aprobación y el organismo competente para su cumplimiento. A su vez, publicará aquellos acuerdos que la insten a dirigirse a otras entidades. 2. A finales de cada año, la Xunta de Galicia elaborará y publicará en el Portal de transparencia y Gobierno abierto un informe respecto al grado de cumplimiento de los acuerdos aprobados por el Parlamento en ese año". Se trata de una transacción con la enmienda del Grupo Parlamentario Mixto núm. 4 de adición.

47 En su trabajo "Transparencia", publicado en Eunomía. Revista en Cultura de la Legalidad, núm. 3, septiembre 2012 -febrero 2013, pp. 160-166.

48 http://www.abogacia.es/2015/03/26/que-podemos-hacer-si-se-incumple-alguna-delas-9-leyes-de-transparencia-que-ya-tenemos-aprobadas-en-espana/ 
Ante esta situación la ley gallega regula del siguiente modo las Reclamaciones frente a las resoluciones en materia de acceso a la información pública. Contra toda resolución expresa o presunta en materia de acceso podrá interponerse una reclamación ante el Valedor do Pobo ${ }^{49}$, excepto en aquellas dictadas por los sujetos previstos en el art. 3.1.d) de la ley, contra las cuales, conforme a lo previsto en la normativa básica, solo cabrá la interposición de recurso contencioso-administrativo. La reclamación ante el órgano independiente de control tendrá:

- la consideración de substitutiva de los recursos administrativos

- un carácter potestativo y previo a la impugnación en vía contencioso-administrativa.

Su procedimiento se ajustará a lo previsto en los números 2,3 y 4 del art. 24 de la Ley 19/2013, del 9 de diciembre, de transparencia, acceso a la información pública y buen gobierno, para las reclamaciones ante el Consejo de Transparencia y Buen Gobierno. Una vez notificadas a las personas interesadas, y después de disociación de los datos de carácter personal que contuviesen, a las resoluciones del Valedor do Pobo por las que se resuelven las reclamaciones de acceso a la información pública:

a. se publicarán en el Portal de transparencia y Gobierno abierto

b. deberán ser tenidas en cuenta por parte de los sujetos que dictasen las resoluciones objeto de reclamación.

Manuel Sánchez de Diego Fernández de la Riva ${ }^{50}$ entendió en su momento que la opción que nuestros legisladores han elegido en relación a la configuración de la transparencia de las administraciones no sigue a la mayoría de la doctrina española, parece desconocer la orientación que las instituciones internacionales atribuyen a la transparencia y olvida la reciente jurisprudencia internacional sobre esta materia. Quizá esta opinión pueda mantenerse respecto de su desarrollo en el Estado de las Autonomías.

\subsection{Coordinación y control de las obligaciones de transparencia}

El texto gallego de 2016 regula los necesarios mecanismos de coordinación y control de las obligaciones de transparencia ${ }^{51}$. Así, en

49 Esta vía de garantía había sido propuesta por Fernández Rodríguez en su obra Defensorías del Pueblo en España: una visión prospectiva, Universidad de Alcalá, 2013, p. 76. En su momento Emilio Guichot señaló que: "la aplicación de las normas de transparencia y acceso a la información tiene importantes implicaciones organizativas, de medios técnicos, materiales y humanos que requiere, que incluyen, entre otros, la creación de mecanismos electrónicos de publicidad activa de permanente actualización y la creación y puesta en funcionamiento del Consejo de Transparencia estatal y sus homólogos autonómicos". En su Estudio de la ley 19/2013, de 9 de diciembre. Tecnos, Madrid, 2014.

${ }^{50}$ Revista jurídica de Castilla y León, núm. 33, mayo 2014.

${ }^{51}$ Francisco Javier Sempere opina que como punto de partida, debemos volver a la Ley 19/2013, de 9 de diciembre, de transparencia, acceso a la información pública y buen gobierno, cuya Disposición Adicional Cuarta, apartado segundo, establece que: "Las Comunidades Autónomas podrán atribuir la competencia para la resolución de la 
primer lugar disciplina el Portal de transparencia y gobierno abierto, en que el sector público autonómico podrá y no deberá dar cuenta de las obligaciones de publicidad activa pues la aceptación de la enmienda 116 del Grupo Parlamentario Mixto en ponencia no llegó a plasmarse en el texto definitivo de la ley ${ }^{52}$. En segundo lugar, organiza los mecanismos internos de coordinación dentro del sector público autonómico para darles cumplimento a las solicitudes de información pública y, por último, de conformidad con la posibilidad regulada en la disposición adicional cuarta de la ley básica, determina el órgano independiente capaz de resolver las reclamaciones sobre resoluciones denegatorias a dichas solicitudes. Para garantizar la auténtica independencia de este órgano, se opta por la atribución de esta competencia al Valedor do Pobo, institución estatutaria de contrastada independencia ${ }^{53}$, al tener garantizado en su ley reguladora que ni su nombramiento ni su cese sean potestad del Gobierno autonómico sino del Parlamento.

Por otro lado el art. 32.1. de la nueva ley, que es un reflejo de la aceptación de la enmienda núm. 3 del Grupo Parlamentario Popular, crea el Comisionado de la Transparencia y se atribuyen las funciones del mismo al Valedor do Pobo. El Comisionado de la Transparencia es el órgano independiente de control del cumplimiento de las obligaciones por parte de los sujetos incluidos en el ámbito de aplicación de la ley y supone una opción legislativa adoptada en la negociación de la ponencia de la ley pues era totalmente desconocida en el texto del proyecto remitido por la Xunta. En este sentido interesa reseñar el contenido de la Disposición final tercera de la ley que procede a la modificación de la Ley 6/1984, de 5 de junio, del Valedor do Pobo y dispone que modifica el art. 10.2 de la Ley 6/1984, de 5 de junio, del Valedor do Pobo, que queda redactado de la siguiente manera:

«2. La plantilla será aprobada por la Mesa del Parlamento a propuesta del valedor o valedora do pobo. Dentro de dicha plantilla el valedor o valedora

reclamación prevista en el art. 24 al Consejo de Transparencia y Buen Gobierno. A tal efecto, deberán celebrar el correspondiente convenio con la Administración General del Estado, en el que se estipulen las condiciones en que la Comunidad sufragará los gastos derivados de esta asunción de competencias". En otras palabras, el Consejo de Transparencia y Buen Gobierno puede hacerse cargo de resolver las denegaciones de acceso a la información de las Comunidades Autónomas previo paso por caja. En caso contrario, búscate la vida creando un órgano o que lo asuma uno ya creado." En "Órganos de control de transparencia administrativa: Consejo de Transparencia y organismos autonómicos", http://www.privacidadlogica.es/2015/01/30/organos-decontrol-de-transparencia-administrativa/

${ }^{52}$ Sin embargo no se incorpora en el art. 29 la petición del Grupo Mixto (enmienda núm. 11) acerca de la constancia de unos estándares de calidad en la información y datos subministrados.

${ }^{53}$ El legislador se muestra confiado en este órgano de control. Mucho más reticente en los controles institucionales, por ejemplo respecto del Tribunal Constitucional se muestra Arce Janáriz en su trabajo "La transparencia de la ley", Revista "Cuadernos Manuel Giménez Abad", núm.. 5, 2013, pp. 59-68. Para un estudio sobre la figura del valedor puede consultarse: X. A. SARMIENTO MÉNDEZ, "O valedor do pobo como garante dos dereitos dos cidadáns galegos", Anuario de la Facultad de Derecho de Ourense, núm.. 1, 2003, pp. 367-390. 
do pobo podrá designar hasta cinco personas asesoras, siempre y cuando sea posible dentro de los límites presupuestarios.

El personal restante habrá de reunir la condición previa de funcionario o funcionaria de cualquiera de las administraciones públicas y podrá ser adscrito a su oficina por libre designación o por concurso público según la relación de puestos de trabajo.»

Esta previsión de dotación de recursos humanos funcionariales para la plantilla del Valedor se muestra como perfectamente razonable habida cuenta de las amplias competencias que de modo totalmente novedoso se le atribuyen a la institución. Su inclusión se debe a la aceptación en el seno de la ponencia de la enmienda núm. 7 de adición del Grupo Parlamentario Popular de Galicia ${ }^{54}$.

El Comisionado de la Transparencia ejercerá las funciones siguientes:

a) Responder a las consultas que, con carácter facultativo, le sean formuladas por los sujetos incluidos en el ámbito de aplicación de la ley.

b) Adoptar recomendaciones para el mejor cumplimiento de las obligaciones legales en materia de transparencia y buen gobierno, oída la Comisión de la Transparencia.

c) Asesorar en materia de transparencia del derecho de acceso a la información pública y buen gobierno.

d) Emitir informe, con carácter previo a su aprobación, sobre proyectos de ley o de reglamentos en materia de transparencia y buen gobierno, oída la Comisión de la Transparencia. Se trata como señala para el caso francés respecto del Consejo de Estado Todorova ${ }^{55}$ de introducir mecanismos de garantía del interés general por la participación en el procedimiento legislativo, realmente en el caso gallego prelegislativo.

e) Efectuar, a iniciativa propia o a causa de denuncia, requerimientos para la subsanación de los incumplimientos que pudieran producirse de las obligaciones establecidas en materia de publicidad activa previstas en la ley.

f) Aquellas otras funciones que le sean atribuidas por una norma legal ${ }^{56}$. Por otro lado se crea mediante la aceptación de la enmienda núm. 4 de adición del Grupo Parlamentario Popular la Comisión de la Transparencia

\footnotetext{
${ }^{54}$ Resulta por lo demás coherente con la aceptación de la enmienda núm. 6 del Grupo Parlamentario Popular que dio lugar a la redacción final de la Disposición adicional sexta. Reasignación de los medios del Valedor do Pobo: "A la entrada en vigor de la presente ley, el valedor o valedora do pobo procederá a la reordenación y reasignación de los medios personales y materiales de la institución para garantizar el cumplimiento de los fines y funciones que esta atribuye al Comisionado de la Transparencia y a la Comisión de la Transparencia".

55 M. TODOROVA, "Le Conseil d'Etat, conseiller du Parlement: premier bilan", Revue française de droit constitutionnel, núm. 93, enero 2013, pp. 125 y ss.

56 El Consejo para la Transparencia chileno dice en su sitio web que "promueve la consolidación de un modelo de gestión gubernamental que, inspirado en el Principio de Transparencia y el Derecho de Acceso a la Información Pública, profundiza la democracia y fomenta la confianza en la función pública sobre la base de la participación y el control ciudadano" en un enfoque muy similar a existente en nuestro entorno. Vid. http://www.consejotransparencia.cl/mision-y-vision/consejo/2012-12-18/193339.html
} 
como órgano colegiado independiente adscrito al Valedor do Pobo ${ }^{57}$. Se compondrá de los siguientes miembros:

a) Presidente o presidenta: el valedor o valedora do Pobo.

b) Vicepresidente o vicepresidenta: el adjunto o adjunta a la institución del Valedor do Pobo.

c) Vocales: una persona representante de la Comisión Interdepartamental de Información y Evaluación de la Xunta de Galicia, una persona representante del Consejo Consultivo de Galicia, una persona representante del Consejo de Cuentas y una persona representante de la Federación Gallega de Municipios y Provincias.

La Comisión de la Transparencia ${ }^{58}$ es el órgano independiente al que corresponde la resolución de las reclamaciones frente a las resoluciones de acceso a la información pública. En caso de empate, el presidente o presidenta tendrá voto dirimente.

Según el texto asumido por la ponencia al aceptarse la enmienda núm. 5 de adición del Grupo Parlamentario Popular el Comisionado de la Transparencia y la Comisión de la Transparencia actuarán con separación de sus funciones respecto a las otras que corresponden al Valedor do Pobo, si bien contarán con los medios personales y materiales asignados a esta institución.

Los sujetos incluidos en el ámbito de aplicación de la ley prestarán la colaboración necesaria al Valedor do Pobo ${ }^{59}$ para el correcto desarrollo de sus funciones, facilitando la información que les solicite en su respectivo ámbito competencial.

La Xunta de Galicia, a través de la Comisión Interdepartamental de Información y Evaluación prevista en el art. 31 de la ley, remitirá al Valedor do Pobo el informe en el cual se analizarán y expondrán, como mínimo, los aspectos siguientes:

\footnotetext{
${ }^{57}$ En la web del defensor andaluz se contiene la siguiente afirmación en relación con la transparencia en aquella comunidad autónoma: "La efectividad de estos derechos requerirá que se instrumenten medidas eficaces de control y garantía de los mismos. A tal fin, el Defensor del Pueblo Andaluz, en el ámbito de sus funciones, velará por la defensa y protección de los mismos, como viene haciendo con todos los derechos estatutarios".

58 El Consejo de Transparencia y Buen Gobierno estatal ha recibido durante 2015 un total de 982 iniciativas ciudadanas, de éstas, 517 fueron reclamaciones, 295 informaciones al ciudadano, 114 consultas sobre la aplicación de la Ley y 26 denuncias por su incumplimiento. Las reclamaciones aumentan conforme el CTB cumple meses en su actividad. Si en el primer trimestre se recibían solo 12 reclamaciones en enero, 35 en febrero y 37 en marzo, en el último trimestre se registraban 57 en octubre, 74 en noviembre y 90 en diciembre. Es decir, en el primer año de funcionamiento del CTB, los ciudadanos casi han triplicado sus reclamaciones a finales de 2015 en relación a las presentadas al comienzo del año, cuando se iniciaba además la actividad del Consejo de Transparencia. El 79,3\% de las reclamaciones presentadas ante el CTB durante 2015 están ya resueltas y el $20,69 \%$ se encuentran todavía en tramitación.

59 Según ha explicado la Defensora del Pueblo española la Ley de Transparencia estatal representa un avance importante y un "buen antídoto contra la corrupción" pues obliga a dar cuenta de cómo se gasta el dinero del contribuyente y a que los datos se expongan claramente. La transparencia también supone "responder a toda la información solicitada" por los ciudadanos.
} 
a) Las estadísticas relativas al derecho de acceso a la información pública, con la inclusión del número de solicitudes presentadas y de los porcentajes de los distintos tipos de resolución a que dieron lugar.

b) Los datos sobre la información más consultada en el Portal de transparencia y Gobierno abierto, y sobre la más solicitada a través del ejercicio del derecho de acceso.

El Valedor do Pobo incluirá, en su informe presentado anualmente ante el Parlamento de Galicia, previsto en el art. 36 de la Ley 6/1984, de 5 de junio, un apartado relativo al grado de aplicación y cumplimiento de la ley, en el que recogerá, en todo caso:

a) Los criterios interpretativos y las recomendaciones que haya formulado durante ese año.

b) La relación de reclamaciones presentadas contra denegaciones de solicitudes de acceso y el sentido de su resolución.

c) La actividad de asesoramiento realizada en materia de transparencia, del derecho de acceso a la información pública y buen gobierno.

d) Los requerimientos efectuados de subsanación de los incumplimientos que pudieran producirse.

e) La evaluación del grado de cumplimiento de las obligaciones de publicidad activa por parte de los distintos sujetos incluidos en su ámbito de aplicación, formulándose requerimientos expresos en el caso de cumplimiento insuficiente.

El informe anual que se presentará al Parlamento estará también a disposición de la ciudadanía dentro del Portal de transparencia y Gobierno abierto, así como en la página web del Valedor do Pobo ${ }^{60}$. No puede desconocerse además que el control del cumplimiento de la ley queda también sujeto como las demás políticas públicas a la actuación de los parlamentarios gallegos, y así pueden destacarse las 16 iniciativas presentadas hasta el día 24 de mayo de 2016 sobre el cumplimiento de la ley autonómica ${ }^{61}$.

En lo referido a los mecanismos de buen gobierno ${ }^{62}$ y control de la actividad de las personas que ocupan altos cargos en el sector público autonómico la ley $1 / 2016$ procede a regular con precisión, en primer lugar, el repertorio de personas que tienen la consideración de alto cargo

\footnotetext{
60 La enmienda 120 del Grupo Parlamentario Mixto aceptada en el seno de la ponencia es la que obliga a esta última previsión de publicidad en el sitio institucional del comisionado parlamentario.

61 La mayor parte de las cuales tratan sobre la publicación de los contratos menores y la información referida a los contratos negociados y que han sido tramitadas como iniciativas de impulso (proposiciones no de ley) o de información (preguntas en pleno, comisión o escritas).

${ }^{62}$ La Unión Iberoamericana de Municipalistas entiende que su Modelo de Buen Gobierno y Calidad Democrática trata de "poner, en suma, a disposición de los gobiernos locales un modelo de excelencia en la gestión que incluya criterios específicos de gestión y de resultados para la calidad democrática y el gobierno del territorio y asumiendo que, para ayuntamientos y municipalidades, se trata más de gobernar que de administrar, ya que gobernar implica ejercer la efectiva capacidad de influenciar y ser protagonista del cambio". Estas ideas ponen de manifiesto el alcance omnicomprensivo del buen gobierno en el derecho comparado.
} 
$y$, después, las obligaciones que las acompañan en el ejercicio de esa responsabilidad, dando rango legal a la necesaria existencia de un código ético institucional ${ }^{63}$ en el campo del sector público autonómico. Fruto de la negociación legislativa en el seno de la ponencia y sin enmienda previa alguna respecto del texto del Gobierno se acordó la inclusión del siguiente texto en el art. 37: "2. La aplicación a los sujetos mencionados en el apartado anterior de las disposiciones contenidas en este título no afectará en caso alguno a la condición de cargo electo que pudieran tener" con lo que se trata de evitar consecuencias en el ámbito de los mandatos representativos emanados de las urnas.

En lo referente a las incompatibilidades, partiendo del principio general de dedicación exclusiva, establece las oportunas, razonables y limitadas excepciones a esta y pasa, a continuación, a potenciar el control sobre los eventuales conflictos de intereses que puedan surgir en el ejercicio de su cargo. Así, se establece como principal novedad respecto de la legislación vigente la obligación de abstenerse en la toma de decisiones relativas a personas jurídicas o entidades privadas de las cuales el alto cargo tuviese parte en su dirección, asesoramiento o administración en los dos años anteriores al nombramiento ${ }^{64}$.

Junto con este ejemplo, el control ${ }^{65}$ sobre los eventuales conflictos de intereses de las personas que ocupan altos cargos se ve ampliado también por la introducción de la obligación para estas personas de tener que informar a la Oficina de Incompatibilidades, durante los dos años siguientes a su cese, de aquellas actividades que vayan a realizar, para que dicha oficina pueda informar sobre su compatibilidad. El Gobierno gallego destacó en el debate de totalidad la limitación que este régimen jurídico supone para la denominada "puerta giratoria" que la opinión pública ha señalado reiteradamente.

El art. 46 referido a la prohibición de la tenencia de fondos en paraísos fiscales establece que:

"Durante el ejercicio de su cargo, así como en los dos años siguientes a su cese, los altos cargos no podrán tener, por sí mismos o por personas o

${ }^{63}$ Cabe destacar la importancia de la concienciación social y la educación en materia de ética pública y así lo han atendido los parlamentos regionales europeos pues nueve de cada diez parlamentos desarrolla actividades dirigidas a los jóvenes, dos puntos más que en 2014. Así en www.calre.eu

${ }^{64}$ Los precedentes remotos de esta regulación están en la derogada Ley 5/2006, de 10 de abril, de regulación de los conflictos de intereses de los miembros del Gobierno y de los altos cargos de la Administración General del Estado que en su Art. 7. Deber de inhibición y de abstención. 1. Disponía:"Quienes desempeñen un alto cargo vienen obligados a inhibirse del conocimiento de los asuntos en cuyo despacho hubieran intervenido o que interesen a empresas o sociedades en cuya dirección, asesoramiento o administración hubieran tenido alguna parte ellos, su cónyuge o persona con quien conviva en análoga relación de afectividad, o familiar dentro del segundo grado y en los dos años anteriores a su toma de posesión como cargo público".

65 Gurrea Bayona afirma que el control externo "forma parte del derecho del buen gobierno, de la buena administración, y de una gobernanza adecuada a los parámetros que nos demanda la UE". Revista aragonesa de Administración pública, Zaragoza 2015, página 366. 
entidades o empresas interpuestas, fondos, activos financieros o valores negociables en países o territorios con calificación de paraíso fiscal según la regulación estatal de aplicación.

En caso de disponer de dichos fondos, activos financieros o valores negociables deberán ponerlo en conocimiento del órgano competente en materia de incompatibilidades y comprometerse a transferirlos a entidades o intermediarios financieros con residencia fiscal en países o territorios que no tengan dicha calificación".

La transacción de la enmienda núm. 50 del Grupo Parlamentario del Bloque Nacionalista Gallego posibilitó la regulación de una temática que no constaba en el texto del proyecto de ley gubernamental.

Finalmente, el control de la actividad de las personas que ocupan altos cargos no se circunscribe únicamente al ámbito interno sino que se hace público a través de la publicidad de la información recogida en las declaraciones de actividades y bienes de estas personas. Por lo tanto, gracias a la publicación de las declaraciones de actividades, la ciudadanía podrá conocer las actividades desarrolladas por cada una de estas personas en los dos años anteriores a su toma de posesión, lo que, sumado a la obligatoria publicación de las resoluciones de compatibilidad aprobadas tras el cese, les proporcionará a las gallegas y a los gallegos una completa información sobre la trayectoria de quien gestiona o gestionó los recursos públicos. Estas ideas refuerzan las demandas de autores como $\mathrm{M}$. Castells ${ }^{66}$ que han enfatizado la necesidad de la cercanía en la gestión de las políticas públicas como vía también para incrementar los controles y evitar la aparición de fenómenos de corrupción.

En lo relativo a las declaraciones de bienes, se extiende la obligación de publicidad que la Ley 14/2013, del 26 de diciembre, de racionalización del sector público autonómico, estableció para los miembros del Gobierno. A partir de la entrada en vigor de esta ley, serán todas las personas que ocupen altos $\operatorname{cargos}^{67}$ las que deban hacer pública su información patrimonial tanto en el momento de su nombramiento como en el de su cese, permitiendo un escrutinio público sobre la evolución de dicho patrimonio.

El Órgano de gestión se denomina Oficina de Incompatibilidades e Boas Prácticas de la Xunta de Galicia y será el órgano competente para:

- la gestión del régimen de incompatibilidades ${ }^{68}$

\footnotetext{
66 "El futuro del Estado del Bienestar en la sociedad informacional", en Buen Gobierno y política social. Editorial Ariel. Barcelona 1997

67 De modo semejante a lo previsto en la Ley 3/2015, de 30 de marzo, reguladora del ejercicio del alto cargo de la Administración General del Estado.

http://www.seap.minhap.gob.es/web/areas/funcion_publica/etica/altos_cargos.html

68 El Informe detallado del grado de cumplimiento de la Ley 3/2015, de 30 de marzo, reguladora del ejercicio del alto cargo de la Administración General del Estado del 1 de enero al 30 junio de 2015. Núm. 0319/2015- del Consejo de Transparencia del Estado admite la reclamación presentada al respecto y la posibilidad de acceso a esa información.
} 
- conocer las denuncias que se puedan formular sobre los presuntos incumplimientos de ese régimen. Estará adscrito a la consellería competente en materia de función pública.

La Oficina de Incompatibilidades e Boas Prácticas da Xunta de Galicia será el órgano encargado del mantenimiento y de la gestión de los registros de actividades y de bienes patrimoniales de altos cargos, y además el responsable de la custodia, seguridad e indemnidad de los datos y documentos que se contengan en ellos. Este órgano será el encargado de cualificar la declaración de actividades y la declaración de bienes patrimoniales en los términos establecidos reglamentariamente ${ }^{69}$. Así mismo, procederá a recordar $y$, de ser el caso, requerir a quien sea nombrado o a quien cese en un cargo de los comprendidos en el ámbito de aplicación o cumplimiento de las obligaciones previstas en la ley.

Se establecen unas obligaciones de información:

a. Todos los órganos de la Administración general de la Comunidad Autónoma, así como todas las entidades del sector público autonómico deberán informar a la Oficina de Incompatibilidades e Boas Prácticas de los nombramientos de los altos cargos comprendidos en el ámbito de aplicación de este título en el plazo de siete días contados desde el nombramiento.

b. Las entidades públicas o privadas con representación del sector público en sus órganos de administración o de gobierno comunicarán ${ }^{70}$ a la Oficina de Incompatibilidades e Boas Prácticas las designaciones de personas que, conforme a lo dispuesto en esta ley, tengan la condición de alto cargo.

c. Todos los altos cargos, entidades, órganos y organismos públicos, así como las entidades privadas tendrán la obligación de colaborar con la Oficina de Incompatibilidades e Boas Prácticas en la obtención de cualquier información que esta les requiera para los efectos de detectar cualquiera vulneración del régimen de incompatibilidades previsto en esta ley. El personal que preste servicios en esta oficina tiene el deber permanente de mantener en secreto los datos y las informaciones que conozca por razón de su trabajo.

\footnotetext{
69 El Consejo de Estado, en su informe sobre la reforma legislativa para regular el ejercicio de los altos cargos, avisó al Gobierno de que ésta suaviza las incompatibilidades profesionales para los ex cargos públicos en los dos años posteriores a su cese al permitirles más actividades que la Ley de regulación de los conflictos de intereses de los miembros del Gobierno y de los altos cargos de la Administración General del Estado aprobada en abril de 2006. Además, el Consejo de Estado también echaba en falta las "reglas" a las que deberá someterse la Oficina de Conflictos de Intereses, la que custodia las declaraciones de los altos cargos, a la hora de abrir un procedimiento sancionador.

${ }^{70}$ En el ámbito estatal se ha aprobado con esa finalidad la Orden por la que se aprueban los modelos de las declaraciones y comunicaciones a las que se refiere la Ley $3 / 2015$, de 30 de marzo, reguladora del ejercicio del alto cargo de la Administración General del Estado. Orden HAP/1176/2015, de 15 de junio (BOE de 19 de junio).
} 
La transacción de las enmiendas 25, 26 y 129 del Grupo Parlamentario Mixto, 53 a 55 del Bloque Nacionalista Galego y 33 del Grupo Parlamentario de Alternativa Galega de Esquerda posibilitó que el Registro de Bienes Patrimoniales de Altos Cargos será público en los términos que se indican en el apartado 4 de su artículo regulador frente al carácter secreto que se contenía en el texto del proyecto de ley.

El contenido de las declaraciones comprensivas de la situación patrimonial estará disponible en el Portal de transparencia y Gobierno abierto y se publicará en el Diario Oficial de Galicia, referido a los momentos del nombramiento y cese de las personas que ocupen altos cargos.

\section{LOS MANDATOS REFERIDOS AL GOBIERNO Y ALTOS CARGOS 3.1. Transición entre gobiernos y buen gobierno}

La ley incide sobre las buenas prácticas específicamente relacionadas con los procesos de transición entre gobiernos. Se trata como ha apuntado Merino Merchán de precisar que el Gobierno en funciones ha de limitar sus competencias al traspaso de poderes y a la gestión del despacho ordinario de los asuntos públicos ${ }^{71}$. Partiendo de la delimitación de la consideración del Gobierno en funciones recogida en el art. 17 del Estatuto de Autonomía de Galicia:

a. se procede a limitar sus facultades durante este período, garantizando que su actividad no pueda condicionar de manera substancial la actividad del Gobierno que lo suceda ${ }^{72}$. De este modo y mediante la aceptación de la enmienda núm. 56, Bloque Nacionalista Galego al apartado 2.b), de Adición del art. 47 del proyecto de ley se limitó también la potestad de "aprobar decretos de desarrollo normativo de leyes u órdenes en ejecución de normas legales o reglamentarias". ${ }^{73}$

b. se regulan las obligaciones de ese gobierno en funciones de que proporcione al futuro Gobierno toda aquella información necesaria para iniciar su gestión, estableciéndose una completa relación de documentación que deberá ser objeto de transmisión durante el proceso de traspaso de poderes entre los gobiernos saliente $y$ entrante.

\footnotetext{
${ }^{71}$ Por esta misma razón entiende que el Gobierno en funciones no puede someterse al control con responsabilidad política pero sí puede ser fiscalizado a través de los instrumentos parlamentarios que implican un control sin responsabilidad política. "Control parlamentario del Gobierno en funciones" en El Notario del Siglo XXI marzo/abril 2016, página 26.

${ }^{72}$ En una línea ya iniciada por la vigente Ley 4/2015, de 26 de febrero, de regulación del proceso de transición entre gobiernos en la Comunidad Autónoma de Extremadura.

73 Del Grupo Parlamentario Bloque Nacionalista Galego se aceptó igualmente la enmienda núm.58, al apartado 2 f) ter), de Adición al originario art. 47.2. para añadir un apartado nuevo que dice: "Resolver expedientes que pongan fin a la aprobación o denegación de planes previstos en la normativa de ordenación territorial o ambiental.
} 
El informe de la Secretaría General del congreso de los diputados de 19 de enero de $2016^{74}$ delimita la cuestión de las consecuencias sobre el ámbito parlamentario de un gobierno en funciones precisando de modo muy razonado aquellas tareas de los parlamentarios que se ven moduladas por las escasas funciones constitucionales que en ese contexto pueden ejercer los ejecutivos.

\subsection{Incompatibilidades y conflictos de intereses}

Con la clara intención de evitar problemas a posteriori la negociación legislativa de la ley posibilitó en la ponencia la transacción de un texto mucho más amplio que el del proyecto en relación al papel del Parlamento de Galicia en la selección de ciertos cargos públicos que aparecen finalmente contenidos en la Disposición adicional tercera. Información previa al Parlamento:

"Con carácter previo al nombramiento de los presidentes o presidentas del Consejo Económico y Social, del Consejo de la Cultura Gallega o de otros órganos que se puedan establecer por ley, y cuyo nombramiento sea realizado por el presidente o presidenta o por el Consejo de la Xunta por un periodo de tiempo determinado, se pondrá en conocimiento del Parlamento de Galicia el nombre de las personas propuestas para estos cargos a fin de que pueda disponer su comparecencia ante la comisión correspondiente de la Cámara. La comisión parlamentaria examinará, en su caso, las candidaturas propuestas. Sus miembros plantearán las preguntas o solicitarán las aclaraciones que crean convenientes.

De igual manera, comparecerán las candidatas o candidatos propuestos para los cargos de director o directora de la Corporación Radio y Televisión de Galicia y valedor o valedora do pobo".

Esta previsión se muestra sensible con demandas doctrinales como las expuestas por el "Grupo de trabajo de participación política: nuevos planteamientos. Subgrupo de participación social en el parlamento"75 que exponen la necesidad de potenciar las comparecencias en Comisión como vía para revivir el papel de las Cámaras parlamentarias en su cercanía a los ciudadanos.

La ley gallega establece el régimen sancionador ${ }^{76}$ derivado de los incumplimientos en materia de incompatibilidades y conflictos de intereses. Así mismo, en desarrollo de las infracciones en gestión económico-presupuestaria y de las infracciones disciplinarias reguladas por la Ley 19/2013, de 9 de diciembre, de transparencia, acceso a la

\footnotetext{
74 https://assets.documentcloud.org/documents/2698134/4-228442704814539247.pdf

${ }^{75}$ Centro de Estudios Políticos y Constitucionales. 28 de enero de 2014.

${ }^{76}$ En el ámbito parlamentario europeo la delimitación y control de responsabilidades se instrumenta muy habitualmente a través de la transparencia y participación pública. De este modo un 27 por ciento de las asambleas legislativas regionales europeas considera que las RRSS favorecen "mucho" el conocimiento de la actividad parlamentaria, y un 47 por ciento cree que lo hacen "bastante". Sin embargo, la mitad (49 por ciento) cree que las Redes Sociales favorecen "poco" o "muy poco" la participación de la ciudadanía en la institución parlamentaria y el 61 por ciento creen que ayudan "poco" o "muy poco" a la recuperación de la confianza en las instituciones.
} 
información pública y buen gobierno, se precisa su procedimiento sancionador, ademáis de incorporar al catálogo de infracciones disciplinarias dispuestas por la ley básica aquellas otras derivadas del incumplimiento de las obligaciones de transparencia previstas en la ley ${ }^{77}$. Soto Lostal ha recordado que el Dictamen del Consejo de Estado de 19 de julio de 2012 sobre el anteproyecto de ley de transparencia, acceso a la información y buen gobierno incide en que "la traslación al ámbito de lo jurídico de normas morales incoercibles puede resultar en determinados caso problemática..." y tal vez por esta constatación el legislador gallego ha optado por una sistematización de conductas y sanciones que logre la efectividad de los genéricos mandatos éticos.

Expertos como Antonio Descalzo se han decantado claramente por postular políticas positivas e incentivos para el logro de los objetivos del buen gobierno, sin embargo la ley gallego diseña un régimen sancionador que se resume en los siguientes puntos:

a. El incumplimiento de las obligaciones establecidas en la ley se sancionaría conforme a lo previsto en el título correspondiente de la norma, sin perjuicio de otras responsabilidades que pudieran concurrir $^{78}$.

b. La potestad sancionadora respecto de las infracciones tipificadas en la ley se ejercerá de conformidad con lo dispuesto en la ley gallega y en la normativa en materia de régimen jurídico de las administraciones públicas y del procedimiento administrativo sancionador $^{79}$. Según Bassols ${ }^{80}$ los criterios de proporcionalidad

77 El Grupo Parlamentario Grupo Mixto logró la incorporación de su enmienda núm.134, al apartado 1, de Substitución por el que fue substituido el texto de la letra d) del apartado 1 del art. 56 por el siguiente:" Una sanción pecuniaria por un importe entre un mínimo del 5 por ciento y un máximo del 10 por ciento de su salario bruto mensual".

${ }^{78}$ Con respecto al borrador presentado en marzo de 2015, los cambios introducidos tras superar la fase de consulta fueron mínimos. El principal es que se suavizó el régimen de sanciones. El texto inicial preveía multas de entre 6.001 y 12.000 euros, además de su cese e inhabilitación, para los altos cargos que cometieran infracciones muy graves, como sacar beneficio para sí mismos o familiares en los actos administrativos o falsear los datos patrimoniales

empresariales.http://www.farodevigo.es/galicia/2015/09/25/xunta-rebaja-sancionesincompatibilidades-altos/1319922.html

79 Uno de los escasos ejemplos de sanción recaída sobre altos cargos es la contenida en la Resolución de 25 de junio de 2014, de la Secretaría de Estado de Administraciones Públicas, por la que se publica la sanción impuesta a don José Enrique Gómez Espinar.

${ }^{80}$ M. BASSOLS COMA, "Buen Gobierno, ética pública y altos cargos", Revista española de Derecho administrativo, núm. 172, 2015, pp. 27 y ss. Resulta llamativa la regulación del código de buen gobierno valenciano de 2016 en el que se prevé que tanto los altos cargos de la Administración de la Generalitat como del sector público instrumental deberán adherirse de forma individualizada y a través de un formulario para poder tomar posesión del cargo. De esta manera se pretende ampliar las posibilidades de control político y, en concreto, de Les Corts. En caso de que un alto cargo contravenga el código se ha previsto un régimen sancionador, un sistema de multas que se enmarca bajo el régimen sancionador de la administración del Estado, que clasifica las sanciones en leves, graves o muy graves. Si la autolimitación política no se ejerce y "se llega a un abuso" provocando una perversión de la transparencia, habrá mecanismos que reorientarán la 
establecidos en el art. 131.3 de la ley 30/1992 pueden bien agravar o atenuar o minorar la responsabilidad si bien parece que habrá de valorarse en todo caso la existencia de perjuicios para el interés público.

c. El régimen sancionador no se aplica si los hechos pueden ser constitutivos de infracción penal y tampoco si, de acuerdo con la ley, puede ser aplicable otro régimen de responsabilidad administrativa ${ }^{81}$ o de naturaleza jurisdiccional, siempre que se dé también la identidad de sujeto y fundamento.

d. Cuando, en cualquier fase del procedimiento sancionador, los órganos competentes consideren que existen elementos de juicio indicativos de la existencia de otra infracción para cuyo conocimiento no sean competentes, se lo comunicarán al órgano que consideren competente.

e. Lo dispuesto en la ley se entiende sin perjuicio de la exigencia de las demás responsabilidades a que hubiera lugar. Para estos efectos, cuando aparezcan indicios de otras responsabilidades, se ordenará a la Asesoría Xurídica de la Xunta de Galicia que valore:

- el ejercicio de otras posibles acciones que puedan corresponder

- si procede, que ponga los hechos en conocimiento del Ministerio Fiscal por si pueden ser constitutivos de delito.

El Grupo Parlamentario Grupo Mixto consiguió la incorporación de su enmienda núm.31, de adición en la redacción final del Art. 61: "Informe al Parlamento de Galicia. La Xunta de Galicia deberá remitir anualmente al Parlamento de Galicia un informe sobre los expedientes tramitados en aplicación del régimen sancionador previsto en este título, incluyendo referencias a los procedimientos iniciados, resueltos y, en su caso, a los que hayan sido objeto de recurso. Este informe se hará público en el Portal de transparencia y Gobierno abierto". Este mandato normativo ha venido a sustituir al informe anual que la Xunta remitía sobre el

tarea del cargo público, pudiendo incluso cesarlo si hubiera una violación grave de este código, según el Consell.

81 "La gran novedad de la propuesta de ley valenciana de incompatibilidades y conflicto de intereses de personas con cargo público es que va más allá del gobierno de la Generalitat, el presidente y los consellers, hasta secretarios autonómicos y directores generales" al incluir por primera vez a funcionarios públicos. Así hace extensiva las incompatibilidades a no sólo los funcionarios que ocupan cargos de libre designación jefes de servicio, subsecretarios o jefes de área, entre ellos sino también a altos funcionarios de la Administración autonómica y local «que perciban retribuciones superiores al nivel de complemento de destino 26». Es decir, todos aquellos empleados públicos del subgrupo $A 1$ que se encuentren entre los tres niveles retributivos del 27 al 30, los más elevados de la función pública." http://www.levante-emv.com/comunitatvalenciana/2015/11/10/futura-ley-incompatibilidades-cargos-publicos/1339472.html 
cumplimiento anual de la normativa de incompatibilidades de miembros del gobierno y altos cargos de la Administración autonómica.

Se precisa que la responsabilidad de la persona titular de la Presidencia da Xunta de Galicia ${ }^{82}$ será la regulada en el Estatuto de Autonomía de Galicia, en el Reglamento del Parlamento de Galicia y en la Ley 1/1983, de 22 de febrero, reguladora de la Xunta y de su Presidencia, cuestión que con carácter general merece opiniones críticas en su regulación por parte de cierta jurisprudencia del Tribunal Supremo español ${ }^{83}$ y que en el derecho comparado ha recibido soluciones muy variadas como las referidas por Rino Casella ${ }^{84}$ en su estudio del caso francés.

En definitiva, la inicial situación de contraposición entre la mayoría y minoría parlamentaria en la sesión del día 10 de noviembre de 2015 en la que se rechazaron las enmiendas a la totalidad del proyecto de ley presentadas por los grupos parlamentarios Mixto, de Alternativa Galega de Esquerda y del Bloque Nacionalista Galego dio paso al estudio y negociación de las 289 enmiendas presentadas al articulado por los cinco grupos parlamentarios lo que devino en un texto altamente modificado sobre el originalmente remitido por el gobierno gallego. Una prueba más de la utilidad y ventajas del "gobierno por la palabra" en que el parlamentarismo gallego consiste y de las mejoras que la negociación legislativa tiene frente a alternativas antiparlamentarias que no han logrado plasmarse en lugar democrático alguno ${ }^{85}$.

\section{BIBLIOGRAFÍA}

ALMONACID, V., "La administración electrónica que soporta la transparencia: una visión jurídico práctica", El consultor de los ayuntamientos, núm. 18, 2015.

ARCE JANÁRIZ, A., "La transparencia de la ley", Revista Cuadernos Manuel Giménez Abad, núm. 5, 2013, pp. 59 y ss.

BARBERA, A., "Da un federalismo insincero ad un regionalismo "preso sul serio"? Una riflessione sull' esperienza regionale", Studi parlamentari e di politica costituzionale, año 44, núm. 171-172, 1-2 trimestre 2011, pp. 19 y ss.

BASSOLS COMA, M., "Buen Gobierno, ética pública y altos cargos", Revista española de Derecho administrativo, núm. 172, 2015, pp. 27 y ss.

\footnotetext{
82 Sobre esta cuestión he escrito "O presidente da Xunta. Delimitación xurídico constitucional da figura", Dereito. Revista xuridica da Universidade de Santiago de Compostela, vol. 11, núm. 2, 2002, pp. 205-231.

83 STS 3 de junio de 2014 en la que se reclama una modificación legislativa de la regulación de los aforamientos en España.

84 CASELLA, Rino, "Francia: la nuova disciplina della responsabilità del Presidente della Repubblica", Studi parlamentari e di politica costituzionale, año 44, núm. 171-172, 1-2 trimestre 2011, pp. 155 y ss.

85 Javier Pardo ha señalado también que la transparencia se constituye en el principio básico y transversal de las últimas reformas ocurridas en el legislativo andaluz (PARDO, Javier, "El Parlamento de Andalucía a través de sus reglamentos". Revista Andaluza de Administración pública, núm. 92, 2015, p. 85).
} 
CACHARRO GOSENDE, F., "La asistencia provincial e insular a los municipios para la aplicación de la ley de transparencia", El consultor de los ayuntamientos, núm. 18, 2015.

CAMPOS ACUÑA, M. C., "Entidades Locales y transparencia. Cinco riesgos a evitar en el proceso de implantación", Revista Española de la Transparencia, núm. 1, 2015, pp. 72 y ss.

CASELLA, R., "Francia: la nuova disciplina della responsabilità del Presidente della Repubblica", Studi parlamentari e di politica costituzionale, año 44, núm. 171-172, 1-2 trimestre 2011, pp. 155 y SS.

CASTELLÁ, B. y TRILLO, V., "La regulación del registro de grupos de interés en la ley 19/2014, del 29 de diciembre, de transparencia, acceso a la información pública y buen gobierno", Revista catalana de dret públic, núm. 51, 2015, pp. 191 y ss.

CASTELLS, M., "El futuro del Estado del Bienestar en la sociedad informacional" en Buen Gobierno y política social, Ariel, Barcelona, 1997.

CIFARELLI, R., "La trasparenza amministrativa dalla legge n. 241/1990 all accesso civico: spunti di riflessione". Studi parlamentari e di politica costituzionale, año 46, núm. 179-180, 2013.

DAVARA RODRÍGUEZ, M. A., "Cuestiones sobre interoperabilidad en las Administraciones Públicas", Actualidad Administrativa, núm. 9, Sección Administración del siglo XXI, septiembre 2015, Editorial La Ley.

DONNARUMA, M. R., "Le régime semi-présidentiel. Une anomalie française". Revue française de droit constitutionnel, núm. 93, 2013, pp. 37 y ss.

FERNÁNDEZ RODRÍGUEZ, J. J., Defensorías del Pueblo en España: una visión prospectiva, Universidad de Alcalá, Alcalá de Henares, 2013.

GARRIDO IGLESIAS, R., "Tecnología para la transparencia legislativa". Serie Bibliotecología y Gestión de Información, Universidad Tecnológica Metropolitana (Chile), Departamento de Gestión de Información, 2014, núm. 86.

GUICHOT, E., Estudio de la ley 19/2013, de 9 de diciembre. Tecnos, Madrid, 2014.

GURREA BAYONA, F., "Organización y funcionamiento de la Cámara de Cuentas de Aragón", Revista aragonesa de Administración pública, núm. 45-46, 2015, pp. 343 y ss.

HERNÁNDEZ JIMÉNEZ, "El Consejo de Transparencia y Buen Gobierno", Actualidad Administrativa, núm. 3, Sección actualidad, marzo 2016, La Ley.

KANT, I., Scritti politici e di filosofia della storia e del diritto, trad. It., Utet, Turín, 1956.

MESA VILA, M., "Algunas cuestiones sobre el ejercicio del derecho de acceso a la información pública en materia de contratos del sector público" Contratación Administrativa Práctica, núm. 139, Sección Contratista versus Administración, septiembre 2015, editorial La ley. 
PARDO, J., "El Parlamento de Andalucía a través de sus reglamentos". Revista Andaluza de Administración pública, núm. 92, 2015.

PIÑAR MAÑAS, J. L., "Seguridad, transparencia y protección de datos: el futuro de un necesario e incierto equilibrio", Laboratorio de Alternativas, núm. 147, 2009.

RIDAO, J., "La regulación de la transparencia y del acceso a la información pública en la esfera autonómica. Un estudio comparado", Revista General de Derecho Constitucional, núm. 19, 2014, pp. 1 y ss.

RUIZ-RICO RUIZ, C., "Transparencia y participación en el derecho autonómico: un análisis constitucional". Revista internacional de doctrina y jurisprudencia, núm. 6, 2014,

SÁNCHEZ DE DIEGO FERNÁNDEZ DE LA RIVA, M., "El día después de la transparencia", Revista jurídica de Castilla y León, núm. 33, mayo 2014.

SANTAOLALLA LÓPEZ, F., "El debate parlamentario y el uso de la palabra", Revista de Derecho Político, UNED, núm. 86, enero-abril 2013, pp. 47 y ss.

SARMIENTO MÉNDEZ, X. A., "As incompatibilidades dos membros da Xunta de Galicia e demáis altos cargos", Dereito. Revista xurídica da Universidade de Santiago de Compostela, vol. 5, núm. 1, 1996, pp. 331 y ss.

SARMIENTO MÉNDEZ, X. A., "O presidente da Xunta. Delimitación xurídico - constitucional da figura", Dereito. Revista xurídica da Universidade de Santiago de Compostela, vol. 11, núm. 2, 2002, pp. 205 y ss.

SARMIENTO MÉNDEZ, X. A., "O valedor do pobo como garante dos dereitos dos cidadáns galegos", Anuario de la Facultad de Derecho de Ourense, núm. 1, 2003, pp. 367 y ss.

TODOROVA, M., "Le Conseil d'Etat, conseiller du Parlement: premier bilan", Revue française de droit constitutionnel, núm. 93, enero 2013, pp. 125 y ss.

VELASCO RICO, C. I., Revista d'Etudis Autonòmics i Federals, núm. 17, abril 2013, pp. 279 y ss.

VILLORIA, M., "El largo camino hacia la transparencia en los ayuntamientos españoles", El consultor de los ayuntamientos, núm. 18,30 de septiembre de 2015. 